\title{
UMA PROPOSTA DE AVALIAÇÃO DE SUSTENTABILIDADE: O SELO LAB-VERDE APLICADO À ESTÂNCIA DEMÉTRIA
}

\author{
Juliana Belko ${ }^{1}$ \\ Luis Felipe Bismarchi² \\ Ligia Perissinoto ${ }^{3}$
}

1 Bacharel em Gestão Ambiental pela Universidade de São Paulo.

2 Administrador FEA-USP, mestre e doutorando PROCAM-USP.

3 Arquiteta e urbanista pela Fundação Armando Álvares Penteado.

\begin{abstract}
Resumo
O presente estudo tem por objetivo apresentar a aplicação dos indicadores de sustentabilidade propostos pelo Selo Lab-Verde da Faculdade de Arquitetura, Urbanismo e Design da Universidade de São Paulo para a Estância Demétria, no município de Botucatu e fazer uma comparação entre a pontuação obtida pelo município de Botucatu em 2010 e pela Estância Demétria atualmente. Os dados referentes a 2010 foram obtidos por pesquisadores do Lab-Verde que pesquisaram a região do Pólo Cuesta, um colegiado de 10 municípios para o desenvolvimento turístico e sustentável da região, incluindo Botucatu. O selo, criado com o intuito de certificar as práticas sustentáveis adotadas por regiões e empreendimentos utiliza critérios para escalas regional, urbana, setorial e local. Paralelamente o artigo traz uma análise destes indicadores propostos pelo selo, reagrupando-os em dimensões de acordo com os pilares do conceito adotado de sustentabildade, quais sejam: Pilar 1 - Demandas Sociais; Pilar 2 - Viabilidade Econômica; Pilar 3 - Prudência Ambiental e Pilar 4 - Decisões Políticas.
\end{abstract}

Palavras-chave: indicadores de sustentabilidade, localização sustentável, Selo LabVerde, escalas de planejamento. 


\title{
A PROPOSAL TO EVALUATE SUSTAINABILY: \\ THE LAB-VERDE CERTIFICATION APPLIED TO ESTÂNCIA DEMÉTRIA
}

\begin{abstract}
The present studie aims to present the application of the sustainability indicators proposed by the University of São Paulo`s Architecture, Urbanism and Design School Lab-Verde`s certification to Estância Demétria, at Botucatu and compare the rating for Botucatu at 2008 and Estância Demetria at present days. The information concerning 2008 was obtained by Lab-Verde researchers that studied the Polo Cuesta, a collegiate of ten (10) cities to develop tourism and sustainability at the region. The certification, created to rate the sustainable practicies adopted by regions and enterprises uses standards for the regional, urban, setorial and local scales. The article also analises this standards regruping them acording to the pilars of the adopted concept of sustainability, namely: Pilar 1 - Social Demands; Pilar 2- Economic Feasibility; Pilar 3 - Ambiental Prudence; Pilar 4 - Politics Desicions.
\end{abstract}

Key-words: sustainability standards, sustainable location, Lab-Verde certification, planning scales.

\section{INTRODUÇÃO}

Vemos que a cada dia o movimento pela sustentabilidade está mais forte na agenda política, na agenda da mídia, em movimentos sociais difusos pelas redes virtuais e em nosso dia a dia. O conceito político de sustentabilidade, estabelecido no final dos anos 80 no Relatório Brundtland, até hoje enfrenta questionamentos tanto de ordem teórica quanto prática.

Se apesar de ser uma forte tendência, ainda assim, o conceito do que é e por que ser sustentável não é um consenso, o que esperar das respostas que são apresentadas ao como ser sustentável ou quanto sustentável ser? Esta sustentabilidade em questão pode contribuir para mitigar o atual impacto das Mudanças Climáticas Globais?

Este artigo busca apresentar uma reflexão sobre o praticar a sustentabilidade. Através de um novo olhar sobre o selo LabVerde desenvolvido por pesquisadores da Faculda- 
de de Arquitetura, Urbanismo e Design da Universidade de São Paulo e pela Faculdade de Arquitetura e Urbanismo da Universidade Mackenzie com o intuito de certificar as práticas sustentáveis adotadas por regiões e empreendimentos levando em conta diversas escalas e tópicos, como gestão de recursos e localização (algo único entre as certificações voltadas à construção civil).

Antes de abordar especificamente o objeto de estudo deste trabalho: o Selo LabVerde aplicado à Estância Demétria, é importante apresentar as bases sob as quais se sustenta este artigo para a execução da proposta de utilizar os indicadores do selo como forma de identificação de oportunidades de ação para promovermos a sustentabilidade em uma região, neste artigo a Estância Demétria.

Para tanto, é necessário apresentarmos o conceito de sustentabilidade que adotamos para este artigo, uma vez que este termo tem muitas interpretações em muitas áreas diferentes. Tal disseminação do conceito foi fomentada pelas constantes catástrofes naturais ao redor do planeta e pelas sensíveis mudanças naturais geradas pelo aquecimento global e outros fenômenos causado pela ação antrópica que fizeram com que nos últimos anos as questões da natureza não ficassem mais restritas aos intelectuais e políticos, passando a ser veiculadas em todos os meios de comunicação de massa o que tem sido um grande estímulo (ou mesmo pressão) para que tanto governos quanto empresas passassem a incorporar os conceitos do desenvolvimento sustentável em suas práticas e modelos de produção e negócio (VEIGA, 2005).

Do conceito de desenvolvimento sustentável apresentado pelo Relatório Brundtland ("desenvolvimento que satisfaz as necessidades presentes, sem comprometer a capacidade das gerações futuras de suprir suas próprias necessidades") depreende-se dois conceitos-chave: a de que as necessidades, em especial a dos mais pobres do mundo, devem receber prioridade máxima e a noção do limite da tecnologia e da organização social, que deve ser imposto de forma a não impedir que as futuras gerações possam também satisfazer suas necessidades (ONU, 1987).

Cabe um destaque quanto à ideia de necessidade, uma construção sociológica e não algo imutável e objetivo. É muito importante que na construção da ideia de sustentabilidade a concepção de necessidade seja repensada (isto é realmente necessário? Do que precisamos efetivamente para viver?), nas palavras de Fry (2005): 


\begin{abstract}
"A necessidade chega até nós de fora para dentro, mais do que de dentro para fora. Ela nos é dada como uma demanda do meio cultural em que nascemos e crescemos (...). Está implícito aqui o fato de que a "necessidade" é, e cada vez mais será, uma categoria contestada (...); colocando de uma forma mais simples, as "necessidades" do mundo dos pobres não são as mesmas dos abastados. Por exemplo, as doenças da abundância e da pobreza não se igualam.
\end{abstract}

Se nós continuarmos a tratar a "necessidade" como se ela fosse um valor imutável e universal (...) não lograremos em conseguir reconhecer e direcionar os problemas mais graves da humanidade.

Para fazer um salto histórico - nós podemos agora reconhecer que na criação, denominação e realização da nossa "necessidade", na chegada da modernidade cultural e econômica, as "necessidades" reais para a sustentação da vida foram tão frequentemente obscurecidas, ignoradas e negligenciadas" (FRY, 2005: 63,64 e 70).

O conceito de DS deve, nos próximos anos, se integrar de forma consistente ao corpo de conhecimentos existente tanto das ciências humanas quanto das naturais, como argumenta Sachs (2002), há a necessidade de "voltar à economia política e a um planejamento flexível negociado e contratual, simultaneamente aberto para as preocupações ambientais e sociais" e reforça a ideia de William Krapp de que há de nascer uma nova disciplina: eco-sócio-economia que buscará integrar de forma viável as demandas ecológicas (descritas pelas ciências naturais) e as demandas sociais e políticas (viabilizadas pelas ciências humanas através da articulação de estratégias nesta direção).

Uma metodologia muito utilizada para explicar a sustentabilidade, retomando a supracitada definição de Sachs (2002) para DS, é o tripple bottom line ou tripé da sustentabilidade proposto por Elkington (1999), segundo esta ideia, a sustentabilidade de um negócio (podendo ser extrapolado para outros níveis, como cidades, estados, países e regiões) se dá a partir do equilíbrio entre três aspectos:

- Os aspectos sociais (people) que englobam todas as pessoas envolvidas direta e indiretamente com as atividades da organização, obedecendo às leis trabalhistas e indo além delas, remunerando de forma honesta e justa e trabalhando pelo bem-estar 
e segurança de seus empregados, suas famílias e todos os outros seres humanos atingidos pelas ações da empresa.

Analogamente, ao tratarmos destes aspectos no planejamento regional, podem os consideradar os indicadores que medem serviços prestados diretamente às pessoas e cujos impactos são mais perceptíveis a elas que à natureza .

- Os aspectos naturais (planet) que englobam todos os recursos naturais e todos os seres vivos afetados direta e indiretamente pela empresa, em outras palavras, as empresas devem minimizar ou se possível anular seus impactos ambientais negativos.

No planejamento regional, podemos considerar os indicadores que medem o impacto direto sobre a natureza e cujos benefícios são sentidos pelas pessoas menos diretamente que os indicadores sociais.

- Os aspectos econômicos (profit) que consiste no resultado financeiro da empresa, o atendimento das expectativas dos acionistas quanto à remuneração do capital investido no empreendimento. É importante ressaltar que para esta metodologia, conhecida também como 3Ps, uma empresa bem sucedida atende positivamente os três aspectos no curto, médio e longo prazo, ou seja, não significa apenas aumentar a riqueza dos acionistas, abandonando todos os outros stakeholders e devastando a natureza.

No planejamento regional, podemos considerar os indicadores que levam em consideração as questões de ganhos econômicos com uso da terra, exploração de recursos ou cobranças por serviços realizados ou prejuízos evitados.

Sachs (2002) apresenta os critérios da sustentabilidade (Quadro 1) distribuídos em 8 dimensões, cada dimensão traz objetivos a serem buscados a fim de construirmos uma sociedade mais sustentável. Estes critérios ainda que qualitativos, servem de orientação para a reflexão de políticas públicas, estratégias corporativas e movimentos sociais em prol do DS e foram considerados na construção da proposta deste trabalho. 
Quadro 4: Critérios da sustentabilidade.

\begin{tabular}{|c|c|}
\hline \multirow[t]{4}{*}{ 1. SOCIAL } & Alcance de um patamar razoável de homogeneidade social; \\
\hline & Distribuição de renda justa; \\
\hline & $\begin{array}{l}\text { Emprego pleno e/ou autônomo com qualidade de vida de- } \\
\text { cente; }\end{array}$ \\
\hline & Igualdade no acesso aos recursos e serviços sociais. \\
\hline \multirow[t]{3}{*}{ 2. CULTURAL } & $\begin{array}{l}\text { Mudanças no interior da continuidade (equilíbrio entre res- } \\
\text { peito à tradição e inovação); }\end{array}$ \\
\hline & $\begin{array}{l}\text { Capacidade de autonomia para elaboração de um projeto } \\
\text { nacional integrado e endógeno (em oposição às cópias ser- } \\
\text { vis dos moldes alienígenas); }\end{array}$ \\
\hline & Autoconfiança combinada com abertura para o mundo. \\
\hline \multirow[t]{2}{*}{ 3. ECOLÓGICA } & $\begin{array}{l}\text { Preservação do potencial do capital da natureza na sua pro- } \\
\text { dução de recursos renováveis; }\end{array}$ \\
\hline & Limitar o uso de recursos não renováveis. \\
\hline 4. AMBIENTAL & $\begin{array}{l}\text { Respeitar e realçar a capacidade de autodepuração dos } \\
\text { ecossistemas naturais. }\end{array}$ \\
\hline \multirow[t]{4}{*}{ 5. TERRITORIAL } & $\begin{array}{l}\text { Configurações urbanas e rurais balanceadas (eliminação } \\
\text { das inclinações urbanas nas alocações do investimento pú- } \\
\text { blico); }\end{array}$ \\
\hline & Melhoria do ambiente urbano; \\
\hline & Superação das disparidades inter-regionais; \\
\hline & $\begin{array}{l}\text { Estratégias de desenvolvimento ambientalmente seguras } \\
\text { para as áreas ecologicamente frágeis (conservação da bio- } \\
\text { diversidade pelo ecodesenvolvimento). }\end{array}$ \\
\hline \multirow[t]{5}{*}{ 6. ECONÔMICO } & Desenvolvimento econômico intersetorial equilibrado; \\
\hline & Segurança alimentar; \\
\hline & $\begin{array}{l}\text { Capacidade de modernização contínua dos instrumentos de } \\
\text { produção; }\end{array}$ \\
\hline & $\begin{array}{l}\text { Razoável nível de autonomia na pesquisa científica e tecno- } \\
\text { lógica; }\end{array}$ \\
\hline & Inserção soberana na economia internacional. \\
\hline
\end{tabular}




\begin{tabular}{|c|c|}
\hline \multirow[t]{3}{*}{$\begin{array}{l}\text { 7. POLÍTICA } \\
\text { (NACIONAL) }\end{array}$} & $\begin{array}{l}\text { Democracia definida em termos de apropriação universal } \\
\text { dos direitos humanos; }\end{array}$ \\
\hline & $\begin{array}{l}\text { Desenvolvimento da capacidade do Estado para implemen- } \\
\text { tar o projeto nacional, em parceira com todos os empreen- } \\
\text { dedores; }\end{array}$ \\
\hline & Um nível razoável de coesão social. \\
\hline \multirow{8}{*}{$\begin{array}{l}\text { 8. POLÍTICA } \\
\text { (INTERNACIONAL) }\end{array}$} & $\begin{array}{l}\text { Eficácia do sistema de prevenção de guerras da ONU, na } \\
\text { garantia da paz e na promoção da cooperação internacional; }\end{array}$ \\
\hline & $\begin{array}{l}\text { Um pacote Norte-Sul de co-desenvolvimento, baseado no } \\
\text { princípio da igualdade (regras do jogo e compartilhamento } \\
\text { da responsabilidade de favorecimento do parceiro mais fra- } \\
\text { co); }\end{array}$ \\
\hline & $\begin{array}{l}\text { Controle institucional efetivo do sistema internacional finan- } \\
\text { ceiro e de negócios; }\end{array}$ \\
\hline & $\begin{array}{l}\text { Controle institucional efetivo da aplicação do Princípio da } \\
\text { Precaução na gestão do meio ambiente e dos recursos na- } \\
\text { turais; }\end{array}$ \\
\hline & Prevenção das mudanças globais negativas; \\
\hline & Proteção da diversidade biológica (e cultural); \\
\hline & $\begin{array}{l}\text { Gestão do patrimônio global como herança comum da hu- } \\
\text { manidade; }\end{array}$ \\
\hline & $\begin{array}{l}\text { Sistema efetivo de cooperação científica e tecnológica in- } \\
\text { ternacional e eliminação parcial do caráter commodity da ci- } \\
\text { ência e tecnologia, também como propriedade da herança } \\
\text { comum da humanidade. }\end{array}$ \\
\hline
\end{tabular}

Extraído de Sachs (2002)

Outra abordagem que busca orientar as estratégias em direção ao desenvolvimento sustentável que vale ser ressaltada é a dos $3 R^{\prime}$ 's da sustentabilidade (PENTEADO, 2003): REDUZIR (o desperdício e até mesmo o consumo), REUTILIZAR (a maior quantidade de material possível) e RECICLAR (dar preferência para produtos que foram ou que podem ser reciclados). $O$ objetivo deste conceito como demonstrado pelo Programa das Nações Unidas para o Meio Ambiente (PNUMA) é o de modificar os padrões de consumo e produção, priorizando o uso de recursos renováveis, recicláveis e reciclados, reuso de materiais e o devido tratamento do lixo, reduzindo assim o uso de recursos e energia, além da produção constante do lixo (UNEP, 2004). 
Manzini e Vezzoli (2002) apontam que existem diversas formas de partir da atual sociedade industrial capitalista em direção a uma sociedade sustentável, lembrando que o desenvolvimento sustentável, ou também sustentabilidade, não é uma direção e sim um objetivo a ser almejado e que deve atender aos seguintes requisitos gerais:

- Basear-se fundamentalmente em recursos renováveis (garantindo ao mesmo tempo a sua renovação);

- Otimizar o emprego dos recursos não renováveis (compreendidos como o ar, a água e o território);

- Não acumular lixo que o ecossistema não seja capaz de renaturalizar (isto é, fazer retornar às substâncias minerais originais e, não menos importante, às suas concentrações originais); e

- Agir de modo com que cada indivíduo, e cada comunidade das sociedades "ricas", permaneça nos limites de seu espaço ambiental e, que cada indivíduo e comunidade das sociedades "pobres" possam efetivamente gozar do espaço ambiental ao qual potencialmente têm direito.

\section{JUSTIFICATIVA}

O Município de Botucatu está localizado na região centro sul do Estado de São Paulo, delimitado pelas coordenadas geográficas 2253'09' latitude Sul e 48²6'42" longitude Oeste. Situa-se a 220 km da capital São Paulo pelas rodovias Marechal Rondon e Castelo Branco. Sua população em 2006 era de praticamente 120.000 habitantes, possuindo uma área de aproximadamente 1.763 km².

A $15 \mathrm{~km}$ do centro de Botucatu encontra-se o o Bairro Demétria, formado em 1980 a partir da interação entre a Estância Demétria, o Sítio Bahia, e outras unidades fundiárias. O Bairro Demétria constitui uma (ZEISA) Zona Especial de Interesse Sócioambiental ao lado dos Bairros: Capão Bonito e Califórnia 1e 2. Segundo o plano Diretor Participativo são Chácaras de Interesse Ambiental (bairros de característica essencialmente rural) em regiões predominantemente localizadas no entorno imediato da cidade, e também na Zona Rural, permitindo-se o exercício das atividades comercial, 
de prestação de serviços, consultorias, e institucional, com prioridade à preservação e conservação ambiental agregada à produção agroecológica.

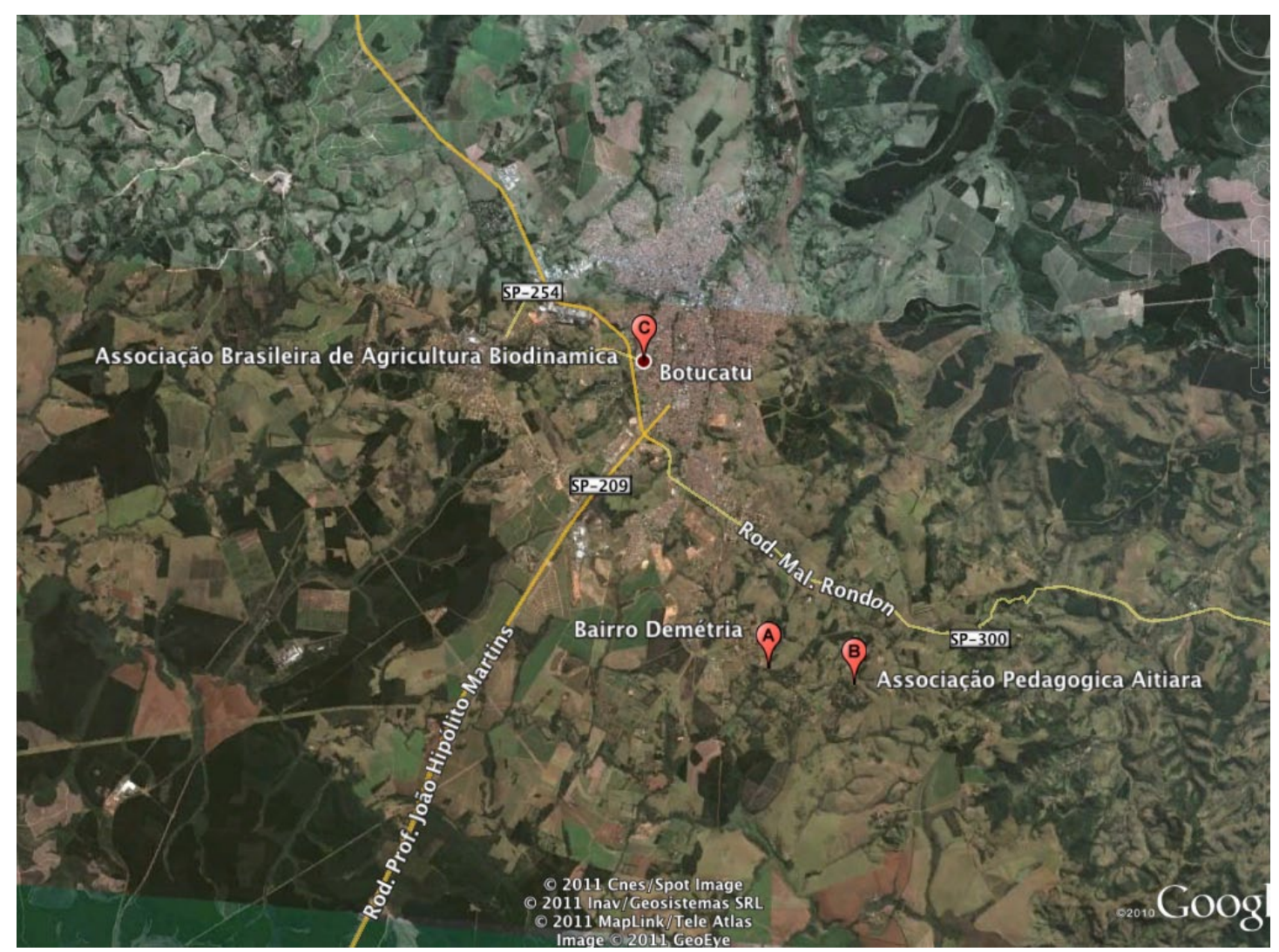

Figura 1: Estradas de acesso ao Bairro Demétria e localização em relação ao centro de Botucatu. Fonte:Goolge Earth.

A Estância Demétria tendo como foco a agricultura biodinâmica, originou-se em 1974 pela aquisição de uma fazenda de cerca de 70 alqueres de terras arenossas degastadas por anos de monocultura do café, por um grupo que em conjunto com a Medicina Antroposófica, a Pedegogia Waldorf e a Euritmia (psicologia e arte terapêutica) compõem os princípios da Antroposofia, criada pelo filósofo austríaco Rudolf Steiner (1861-1925).

Neste contexto foi construída a Escola Aitiara com os princípios da pedagogia Waldorf, uma loja de produtos naturais e orgânicos, pousadas e casas para receber visitantes, restaurantes e constituiram-se associações entre os moradores. 


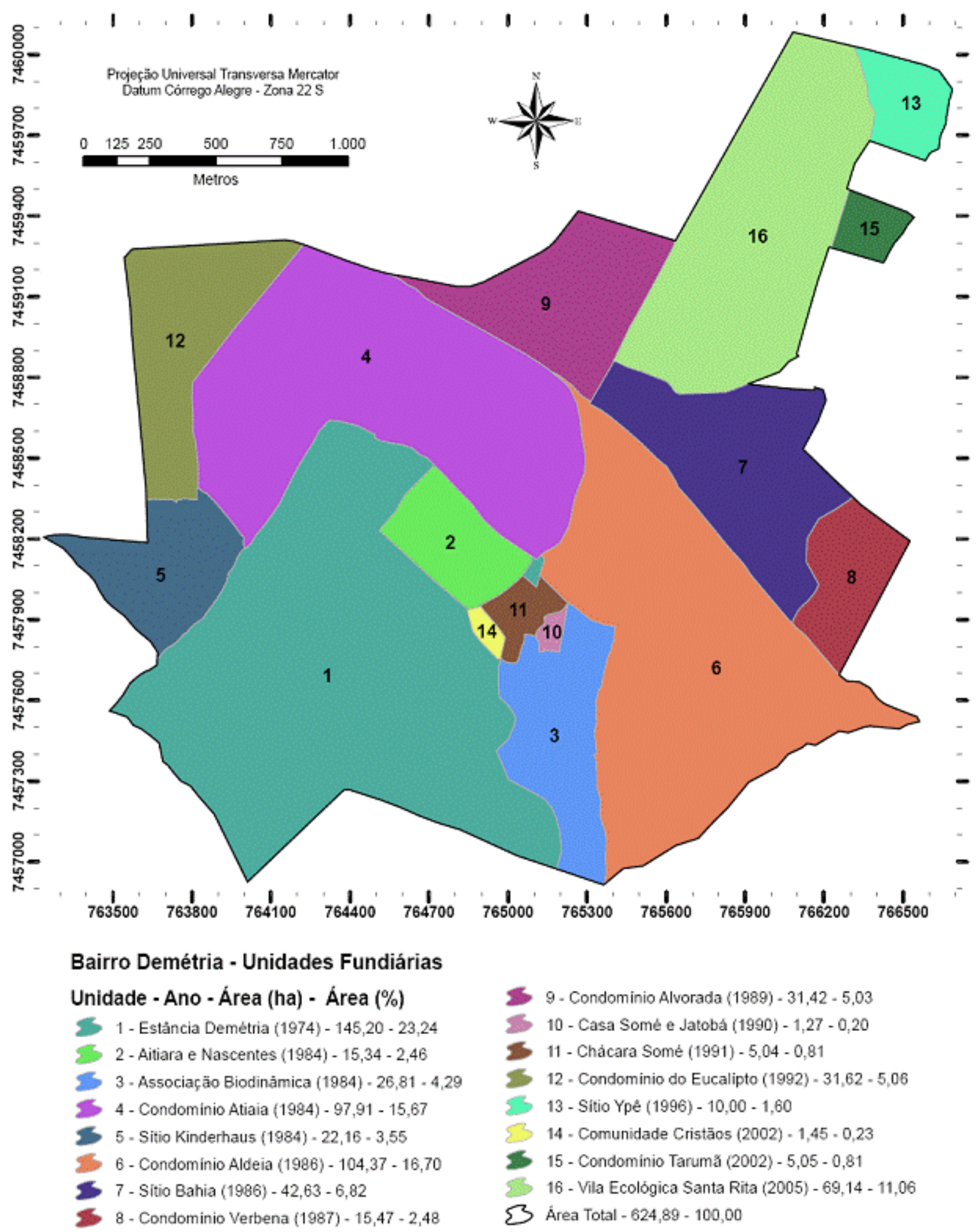

Figura 2: Unidades Fundiárias do Bairro Demétria. Fonte: Bertalot-Bay, 2008

Este artigo propõe-se a estudar a Estância Demétria, composta pela própria estância e pela anexação do Sítio Bahia quanto aos aspectos sustentáveis abordados pelo Selo Lab-Verde nas escalas Regional, Urbana, Setorial e Local e comparar seus in- 
dicadores de sustentabilidade com os do município de Botucatu, onde está inserido. Isto pela origem sustentável, importância local da Estância e importância de atual de atitudes individuais e coletivas que visem a diminuir as consequências da mudanças climáticas.

Ainda na escala local (projeto sustentável, construção verde e tecnologia), propomos um recorte na Escola Waldorf do bairro para verificar seu alinhamento com os tópicos de sustentabilidade do Selo Lab-Verde. Iremos propor ainda que se avalie também a escolha dos materiais utilizados na construção (disponibilidade local e transporte) e o envolvimento comunitário no projeto e construção, considerando que este envolvimento represente o fator social do tripé "ambiental, social, econômico" que compõe o conceito de sustentabilidade.

\section{METODOLOGIA}

Para este trabalho inicialmente pesquisamos o conceito de sustentabilidade, sua origem e formas de mensuração. A partir desta pesquisa resolvemos trabalhar com os indicadores do Selo Lab-Verde.

Os indicadores do Selo Lab-Verde foram desenvolvidos pelo Lab-Verde da Faculdade de Arquitetura, Urbanismo e Design da Universidade de São Paulo propostos para mensurar a sustentabilidade de uma determinada localidade nas escalas regional, urbana, setorial e local. Aplicados inicialmente para os municípios do Pólo Cuesta pelos estudantes do laboratório nos anos de 2008 e 2010 estes indicadores foram utilizados para mensurar a sustentabilidade da Estância Demétria e comparar a sua sustentabilidade com a do município de Botucatu em 2010.

Para a comparação com o município de Botucatu utilizamos o trabalho realizado pelos alunos do Laboratório no ano de 2010 que aplicou o Selo Lab-Verde para o município. Já para a mensuração desses indicadores na Estância Demétria entrevistou-se moradores da Estância envolvidos nas atividades comerciais, agrícola e pedagógica, consultou-se dados bibliográficos de fonte acadêmicas e de sites na internet.

A partir das pontuações obtidas para Botucatu em 2010 e a Estância Demétria no presente, construímos um gráfico radar através do software Excel para a comparação dos dados. 
Apresentada a ideia de sustentabilidade que será adotada neste trabalho: a busca de soluções que promovam um equilíbrio entre demandas sociais, viabilidade econômica e prudência ambiental, passaremos à definição de como mediremos se uma ação é mais ou menos aderente a esta conceito de sustentabilidade.

Tomaremos como base o trabalho realizado pelo grupo LabVerde da FAU-USP que definiram critérios para avaliação e certificação de sustentabilidade a regiões, municípios e localidades.

O Selo Lab-Verde foi criado como um experimento, no início de 2008, pelo LAb-Verde da FAU-USP e FAU-Mackenzie, destinado à avaliação e certificação ambiental de empreendimentos e projetos com ênfase em localização sustentável. Os critérios de pontuação baseiam-se nos princípios da Agenda 21 e do Protocolo de Kyoto e percorrem várias escalas de atuação, dependendo do projeto em análise. De maneira geral os projetos são vistos através de parâmetros das áreas de: Planejamento e Gestão Ambiental na escala regional; Desenho Ambiental nas escalas urbana e setorial; e Projeto Sustentável na escala local.

Os indicadores utilizados são:

\section{ÁREA: Planejamento e Gestão Ambiental (escala regional)}

1- Gestão de bacias baseada em Associação de Municípios

2- Conservação dos aqüíferos e águas superficiais

3- Preservação e Conservação da paisagem e da biota regional

4- Destino, coleta e reciclagem do lixo

5- Geração de energias renováveis

6- Produção de alimentos "in loco"

7- Controle da expansão urbana

8- Envolvimento comunitário

\section{DESENHO AMBIENTAL (escala urbana)}

1- Re-qualificação de áreas degradadas

2- Locações preferenciais

3- Criação e conservação de sistemas de parques e áreas verdes

4- Rede de ciclovias eficiente

5- Habitação, escola e trabalho próximos

6- Proteção a áreas de encostas 
7- Manejo de enchentes

8- Projeto do sítio para recuperação, conservação e manejo de habitat e áreas úmidas

\section{DESENHO AMBIENTAL (escala setorial)}

1 - Desenvolvimento compacto

2 - Diversidade de usos

3 - Acessibilidade a diversos tipos de moradia

4 - Ruas de pedestres

5 - Rede viária eficiente para ciclovia

6 - Redução da poluição visual

7 - Acessibilidade universal

8 - Comunidade envolvida

PROJETO SUSTENTÁVEL (escala local) - construção verde e tecnologia

1- Eficiência de energia nos edifícios

2- Captação de águas pluviais e redução do uso da água

3- Reuso de edifícios e adaptação de reuso

4- Minimização de distúrbios durante a construção

5- Descontaminação na recuperação de solos degradados

6- Redução da 'ilha de calor'

7- Fontes de energias renováveis 'in loco'

8- Coleta seletiva do lixo

Como parte do objetivo deste artigo, reorganizamos estes indicadores em pilares de sustentabilidade baseados nos conceitos apresentados anteriormente da seguinte maneira:

Pilar 1 - Demandas Sociais (considerados os indicadores que medem serviços prestados diretamente às pessoas e cujos impactos são mais perceptíveis a elas que à natureza)

1 - Rede de ciclovias eficiente

2 - Habitação, escola e trabalho próximos

3 - Acessibilidade a diversos tipos de moradia

4 - Ruas de pedestres

5 - Rede viária eficiente c/ ciclovia

6 - Redução da poluição visual 


\section{7 - Acessibilidade universal}

8 - Minimização de distúrbios durante a construção

Pilar 2 - Viabilidade Econômica (considerados os indicadores que levam em consideração as questões de ganhos econômicos com uso da terra, exploração de recursos ou cobranças por serviços realizados ou prejuízos evitados)

1 - Diversidade de usos (escala setorial)

Pilar 3 - Prudência Ambiental (considerados os indicadores que medem o impacto direto sobre a natureza e cujos benefícios são sentidos pelas pessoas menos diretamente que os indicadores sociais)

1 - Conservação dos aqüíferos e águas superficiais

2 - Preservação e Conservação da paisagem e da biota regional

3 - Destino, coleta e reciclagem do lixo

4 - Geração de energias renováveis

5 - Produção de alimentos "in loco"

6 - Controle da expansão urbana

7 - Re-qualificação de áreas degradadas

8 - Proteção a áreas de encostas

9 - Manejo de enchentes

10 - Projeto do sítio para recuperação, conservação e manejo de habitat e áreas úmidas

11 - Eficiência de energia nos edifícios

12 - Captação de águas pluviais e redução do uso da água

13 - Reuso de edifícios e adaptação de reuso

14 - Descontaminação na recuperação de solos degradados

15 - Redução da 'ilha de calor'

16 - Fontes de energias renováveis 'in loco'

17 - Coleta seletiva do lixo

Pilar 4 - Decisões Política (considerados os indicadores que medem a participação das pessoas nos processos decisórios e medem o grau de permeabilidade do Estado e das empresas à influência e opinião de todos os cidadãos interessados)

1 - Gestão de bacias baseada em Associação de Municípios

2 - Envolvimento comunitário 
3 - Locações preferenciais

4 - Criação e conservação de sistemas de parques e áreas verdes

5 - Desenvolvimento compacto

6 - Comunidade envolvida

Os indicadores reorganizados nas quatro dimensões apresentadas acima, tiveram seu valor ponderado pelo peso que possuem na composição da pontuação total possível da dimensão que fazem parte e a pontuação geral foi obtida com a soma ponderada dos subtotais das dimensões para que todas as dimensões tivessem o mesmo peso.

Por exemplo, o indicador Rede de Ciclovias Eficiente tem pontuação máxima de 2 pontos e faz parte da dimensão social que possui um total possível de 22 pontos, Botucatu recebeu 0,5 ponto na avaliação de 2010 , a ponderação para classificação deste indicador segundo a metodologia adotada é $0,5 / 22=0,0227$. O subtotal da dimensão social de Botucatu foi 0,5455 que foi ponderado pelo peso 0,25 totalizando 0,1364 pontos.

A partir da pontuação ponderada de cada indicador foram elaborados os gráficos radar comparativo do município de Botucatu e a estância Demétria.

\section{OS INDICADORES DO LAB-VERDE APLICADOS À ESTÂNCIA DEMÉTRIA}

Através de entrevista com moradores da Estância Demétria e pela consulta de dados secundários existentes sobre a região foi possível fazer um quadro sobre a sustentabilidade da Estância Demétria a partir dos indicadores desenvolvidos pelo Lab-Verde.

Os indicadores do selo Lab-Verde foram utilizados com o intuito de medir a sustentabilidade da Estância Demétria nas escalas regional, urbana, setorial e local, esta último tomando por base, principalmente, a Escola Aitiara de Pedagogia Waldorf e complementada a pontuação dos indicadores através da observação de outras edificações.

Embora não tenha sido possível localizar alguém que participe de comitês de bacias ou outros meios de gestão das águas na escala intermunicipal, quanto à preservação das águas superficiais e subterrâneas observa-se dentro da Estância o respeito pelas Áreas de Preservação Permanente, a não utilização de agrotóxicos nas plantações, 
o que evita a contaminação do solo e de aquíferos e o aproveitamento das fezes dos bovinos para compostagem de forma a diminuir a poluição dos solos e águas subterrâneas por estes animais.

Se por outro lado as primeiras e mais antigas residências da fazenda apresente fossas negras, estas estão sendo paulatinamente substituídas por fossas sépticas pela preocupação com a poluição dos solos e águas subterrâneas. O que coincide com a existência de uma ONG para a preservação ambiental e recuperação de aquíferos da região dentro da Estância, a ONG Nascentes.

Quanto às áreas florestadas, a localidade teve um aumento dessas áreas desde 1972, dois anos antes da aquisição da fazenda pelo grupo de agricultura biodinâmica em 2005, observando-se também o respeito pelas Áreas de Preservação Permanentes. Da mesma forma, para a construção das moradias e edifícios necessários à fazenda é notória a conservação da vegetação nativa e busca por locais adequados, sem risco de erosão ou alagamentos (Bertalo-Bay, 2008).

A questão dos resíduos sólidos urbanos é tratada com seriedade na Estância, havendo coleta seletiva de lixo, utilização de esterco do gado para geração de energia elétrica e alimentação de porcos com sobras da fábrica de geleias. A mesma preocupação se aplica à geração de energia alternativa com o aquecimento de água através de placas solares nos estábulos, na casa grande e na casa de um dos moradores.

No entanto, quanto ao controle do número de habitantes, por não haver densidade e número de moradores suficiente nas atividades econômicas locais seus moradores veem a necessidade de mais moradores no local. Tal postura por parte dos moradores atuais não implica na perda pela preocupação com a conservação da vegetação nativa, pela recuperação do solo, antes bastante prejudicado por plantações de café e pela diversidade de atividades sendo elas a venda dos alimentos e produtos ali cultivados e produzidos, entre eles pães, mel, geléias, laticínios, restaurantes e pousadas.

Quando se aborda a questão do envolvimento comunitário, temos contabilizadas dez associações e instituições locais, o que indica grande envolvimento comunitário devido à quantidade limitada de pessoas e ao afastamento físico de suas residências, as associações existentes são: Escola Aitiara, Associação Brasileira de Agricultura Biodinâmica, Associação Instituto Biodinâmico, Instituto Elo de Economia Associativa, Comunidade de Cristãos, Associação dos Moradores e Amigos do Bairro Demétria 
(AMA-Demétria), ONG Nascentes, Curso de Formação de Euritmia, Associação Adão e Ema e a Escola de samba "Unidos da Demétria".

$\mathrm{Na}$ estância existem vias de acesso a todas edificações, para este acesso é necessária a utilização de automóveis, bicicletas que dividem o espaço com os primeiros ou a pé. Para o acesso a pé é possível a utilização de caminhos alternativos entre as casas, já para as bicicletas o espaço tem que ser dividido com os automóveis, pois ainda está em planejamento junto à prefeitura a construção de ciclovias para todo o Bairro Demétria, havendo grande interesse por parte dos moradores.

A partir da realização de entrevista com um dos gestores da escola foi possível identificar que dentre os indicadores propostos na escala local do Selo Lab-Verde, a gestão dos resíduos sólidos é o tema onde a escola mais se destaca: possuem coleta seletiva de lixo, e encaminham os resíduos para reciclagem ou compostagem e dispõem de local adequado para armazenar os resíduos até sua retirada.

Para o indicador envolvimento comunitário, a escola também apresenta bons resultados, pois durante a construção houve o envolvimento de moradores do bairro e do entorno, alunos e pais de alunos, gestores e comunidade escolar por meio de reuniões para discussão sobre localização do edifício/escolha do terreno, definição do programa de necessidades, escolha de técnicas construtivas/materiais, projeto e construção. O edifício foi construído para abrigar a escola e é utilizado para outras atividades fora dos horários de aula.

Os materiais escolhidos para a construção foram: tijolo cozido aparente e madeira. Uma análise mais aprofundada seria necessária para checar a procedência da madeira e então classificá-la de acordo com o indicador. O critério de escolha dos materiais foi sua pertinência aos princípios da arquitetura antroposófica.

Com relação à eficiência energética e fontes de energia renovável in loco, a escola não conta com sistemas de geração própria de energia no edifício, tanto elétrica como para aquecimento de água, e sua arquitetura não apresenta medidas de redução de consumo, como iluminação natural, porém são utilizadas lâmpadas de baixo consumo. Foi relatado que no sítio Bahia existe coletor de luz solar para aquecimento de água. 
Com relação ao abastecimento de água, de acordo com as respostas fornecidas, o edifício não conta com sistemas de reciclagem de águas servidas, captação de águas pluviais ou dispositivos de redução de consumo. Foi relatada a presença de coletores de água pluvial no estábulo e outras edificações do sítio Bahia.

Para os indicadores Ilha de Calor e Minimização de distúrbios durante a construção não foram obtidas respostas, portanto, foram utilizados os mesmos valores associados ao município de Botucatu onde se insere a estância Demétria.

\section{COMPARAÇÃO ENTRE OS RESULTADOS DA ESTÂNCIA DEMÉTRIA E O MUNICÍPIO DE BOTUCATU}

Abaixo apresentamos as tabelas com os valores comparativos dos indicadores do Lab-Verde para a Estância Demétria e para o município de Botucatu.

\begin{tabular}{|l|r|r|r|}
\hline INDICADORES & DEMÉTRIA & BOTUCATU & $\begin{array}{l}\text { PONTOS } \\
\text { MAX. }\end{array}$ \\
\hline Planejamento e Gestão Ambiental (esc. regional) & 2 & 2 \\
\hline Gestão de bacias baseada em Associa ção de Municípios & 3 & 1,5 & 3 \\
\hline Conservação dos aqüiferos e águas superficia is & 3 & 2 \\
\hline Preservação e Conservação da paisagem e da biota regional & 2 & 1,5 & 3 \\
\hline Destino, coleta e reciclagem do lixo & 1 & 0,5 & 2 \\
\hline Geração de energias renováveis & 2 & 1,5 & 2 \\
\hline Produção de alimentos "in loco" & 0,1 & & 1 \\
\hline Controle da expansão urbana & 2 & 2 \\
\hline Envolvimento comunitário & 15,1 & 11 & 2 \\
\hline
\end{tabular}

\begin{tabular}{|c|c|c|c|}
\hline DESENHO AMBIENTAL (esc. Urbana) & DEMÉTRIA & BOTUCATU & $\begin{array}{l}\text { PONTOS } \\
\text { MAX. }\end{array}$ \\
\hline Re-qualificação de áreas degradadas & 2 & 1,5 & 2 \\
\hline Locações preferenciais & 4 & 3 & 4 \\
\hline Cria ção e conservação de sistemas de parques e áreas verdes & 3 & 2,5 & 3 \\
\hline Rede de ciclovias eficiente & 1 & 0,5 & 2 \\
\hline Habita ção, escola e trabalho próximos & 2 & 3 & 3 \\
\hline Proteção a áreas de encostas & 2 & 2 & 2 \\
\hline Manejo de enchentes & 2 & 1 & 2 \\
\hline $\begin{array}{l}\text { Projeto do sítio para recuperação, conservação e manejo de } \\
\text { habitat e áreas úmidas }\end{array}$ & 2 & 1,5 & 2 \\
\hline & 18 & 15 & 20 \\
\hline
\end{tabular}




\section{Revista LABVERDE}

\begin{tabular}{|c|c|c|c|}
\hline PROJETO SUSTENTÁVEL(escala local) & DEMÉTRIA & BOTUCATU & $\begin{array}{l}\text { PONTOS } \\
\text { MAX. }\end{array}$ \\
\hline Eficiência de energia nos edifícios & 1 & 3 & 6 \\
\hline Captação de águas pluvia is e redução do uso da água & 0,1 & 2 & 6 \\
\hline Reuso de edifícios e adaptação de reuso & 2 & 3 & 4 \\
\hline Minimiza ção de distúrbios durante a construção & $\mathbf{0 . 5}$ & 0,5 & 2 \\
\hline Descontaminação na recuperação de solos degradados & $\mathbf{z}$ & 2 & 3 \\
\hline Redução da 'ilha de calor' & $\mathbf{z}$ & 2 & 3 \\
\hline Fontes de energias renováveis 'in loco' & 0,1 & 1,5 & 3 \\
\hline Coleta seletiva do lixo & 3 & 2 & 3 \\
\hline Subtotais & 10,7 & 16 & 30 \\
\hline Total & 60,9 & 61 & 100 \\
\hline
\end{tabular}

Conforme a reclassificação dos indicadores, apresentamos estes pelos quatro pilares propostos:

\begin{tabular}{|l|r|r|r|c|c|}
\hline \multicolumn{1}{|c|}{ Social } & Total & De métria & Botucatu & Botucatu & Demétria \\
\hline Rede de ciclovias eficiente & 2 & 1 & 0,5 & 0,0227 & 0,0455 \\
\hline Habitação, escola e trabal ho próximos & 3 & 2 & 3 & 0,1364 & 0,0909 \\
\hline Ace ssibilidade a diversos tipos de moradia & 3 & 3 & 3 & 0,1364 & 0,1364 \\
\hline Ruas de pedestres & 3 & 1 & 1 & 0,0455 & 0,0455 \\
\hline Rede viária eficiente c/ ciclovia & 3 & 1 & 1 & 0,0455 & 0,0455 \\
\hline Redução da poluição visual & 3 & 3 & 1,5 & 0,0682 & 0,1364 \\
\hline Acessibilidade universal & 3 & 1 & 1,5 & 0,0682 & 0,0455 \\
\hline Minimização de distúrbios durante a construção & 2 & 0,5 & 0,5 & 0,0227 & 0,0227 \\
\hline Subtotal Social & 22 & 12,5 & 12 & 0,5455 & 0,5682 \\
\hline
\end{tabular}

\begin{tabular}{|l|r|r|r|r|r|}
\hline Econômica & Total & De métria & Botucatu & Botucatu & Demétria \\
\hline Diversidade de usos & 6 & 5 & 6 & 1,000 & 0,833 \\
\hline Subtotal Econômica & 6 & 5 & 6 & 1,000 & 0,833 \\
\hline
\end{tabular}




\begin{tabular}{|l|r|r|r|r|r|}
\hline Ambiental & Total & De métria & Botucatu & Botucatu & Demétria \\
\hline Conservação dos aqǘferos e águas supe rficiais & 3 & 3 & 1,5 & 0,0294 & 0,0588 \\
\hline Pre servação e Conservação da paisagem e da bi ota regional & 3 & 3 & 2 & 0,0392 & 0,0588 \\
\hline Destino, coleta e reciclagem do lixo & 3 & 2 & 1,5 & 0,0294 & 0,0392 \\
\hline Geração de energias renováveis & 2 & 1 & 0,5 & 0,0098 & 0,0196 \\
\hline Produção de alimentos "in loco" & 2 & 2 & 1,5 & 0,0294 & 0,0392 \\
\hline Controle da expansão urbana & 2 & 0,1 & 1 & 0,0196 & 0,0020 \\
\hline Re-qualificação de áreas degradadas & 2 & 2 & 1,5 & 0,0294 & 0,0392 \\
\hline Proteção a áreas de encostas & 2 & 2 & 2 & 0,0392 & 0,0392 \\
\hline Manejo de enchentes & 2 & 2 & 1 & 0,0196 & 0,0392 \\
\hline Projeto do sítio para recu peração, conservação e manejo de & & & & & \\
habitat e áreas úmidas & 2 & 2 & 1,5 & 0,0294 & 0,0392 \\
\hline Eficiência de energia nos edifícios & 6 & 2 & 3 & 0,0588 & 0,0392 \\
\hline Captação de águas pluviais e redução do uso da água & 6 & 2 & 2 & 0,0392 & 0,0392 \\
\hline Reuso de edifícios e adaptação de reuso & 4 & 2 & 3 & 0,0588 & 0,0392 \\
\hline Descontaminação na recuperação de solos degradados & 3 & 2 & 2 & 0,0392 & 0,0392 \\
\hline Redução da 'ilha de calor' & 3 & 2 & 2 & 0,0392 & 0,0392 \\
\hline Fontes de energias renováveis 'in loco' & 3 & 0,1 & 1,5 & 0,0294 & 0,0020 \\
\hline Coleta sele tiva do lixo & 3 & 3 & 2 & 0,0392 & 0,0588 \\
\hline Subtotal Ambiental & 51 & 32,2 & 29,5 & 0,5784 & 0,6314 \\
\hline
\end{tabular}

\begin{tabular}{|l|r|r|r|r|r|}
\hline Política & Total & De métria & Botucatu & Botucatu & Demétria \\
\hline Gestão de bacias baseada em Associação de Municípios & 3 & 2 & 2 & 0,0952 & 0,0952 \\
\hline Envolvime nto comunitário & 2 & 2 & 1 & 0,0476 & 0,0952 \\
\hline Locações preferenciais & 4 & 4 & 3 & 0,1429 & 0,1905 \\
\hline Criação e conservação de sistemas de parques e áreas verdes & 3 & 3 & 2,5 & 0,1190 & 0,1429 \\
\hline Desenvolvimento compacto & 6 & 0,1 & 3 & 0,1429 & 0,0048 \\
\hline Comunidade envolvida & 3 & 3 & 2 & 0,0952 & 0,1429 \\
\hline Subtotal Política & 21 & 14,1 & 13,5 & 0,6429 & 0,6714 \\
\hline
\end{tabular}

\begin{tabular}{|l|r|r|r|r|r|}
\hline TOTAL & 100 & 63,8 & 61 & 0,61 & 0,638 \\
\hline
\end{tabular}

\begin{tabular}{|l|r|r|r|r|r|}
\hline & Total & De métria & Botucatu & Botucatu & Demétria \\
\hline Subtotal Social & 22 & 12,5 & 12 & 0,1364 & 0,1420 \\
\hline Subtotal Econômica & 6 & 5 & 6 & 0,2500 & 0,2083 \\
\hline Subtotal Ambiental & 51 & 32,2 & 29,5 & 0,1446 & 0,1578 \\
\hline Subtotal Política & 21 & 14,1 & 13,5 & 0,1607 & 0,1679 \\
\hline Total & 100 & 63,8 & 61 & 0,6917 & 0,6761 \\
\hline
\end{tabular}

Comparando a pontuação total ponderada das dimensões da sustentabilidade avaliadas, obtemos o gráfico comparativo abaixo: 


\section{Revista LABVERDE}

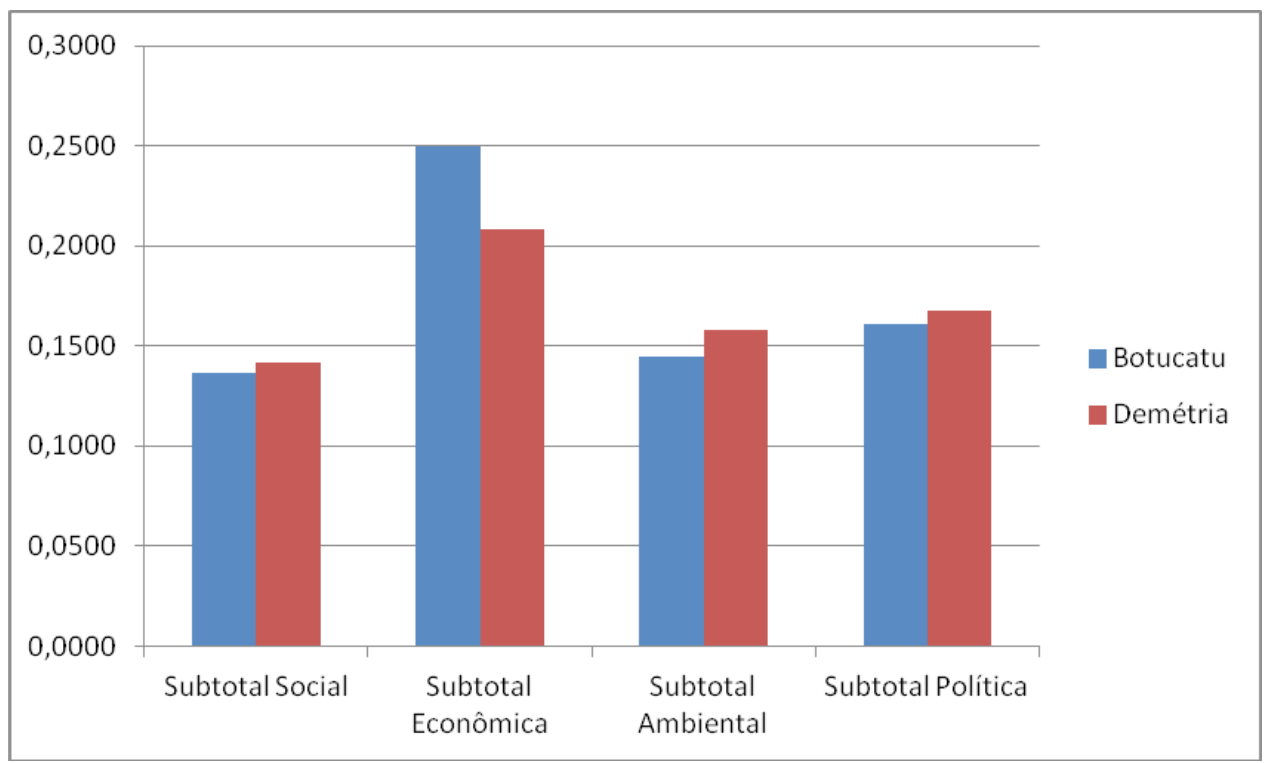

Ao aplicarmos a pontuação obtida nestes indicadores, redistribuídos como sugerido, e ponderados pela sua representatividade no total obtemos:

\section{Gráfico Pontuação Estância Demétria x Botucatu}

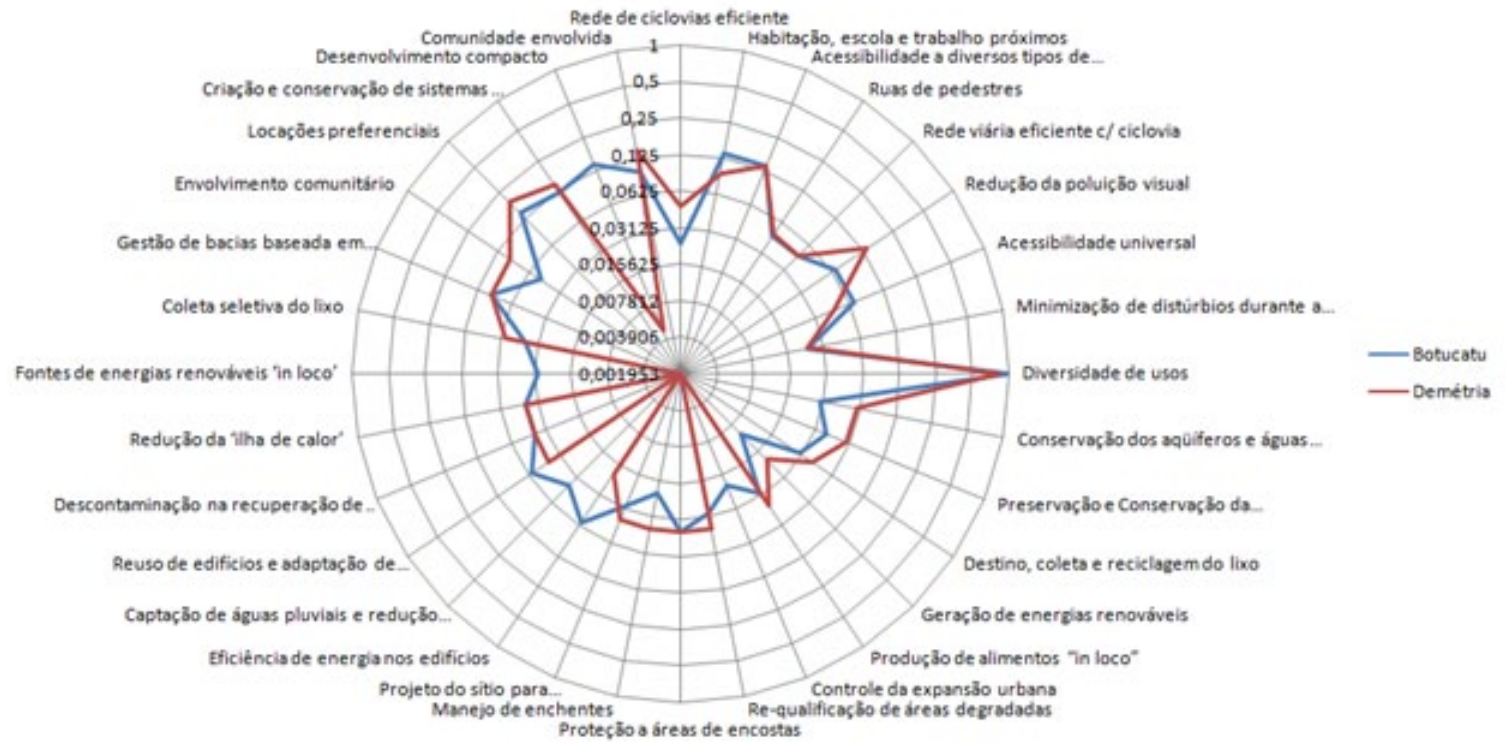




\section{DISCUSSÃO E CONSIDERAÇÕES FINAIS}

A primeira avaliação que podemos fazer da reorganização dos indicadores nas quatro dimensões de sustentabilidade é que a dimensão econômica é a menos avaliada (apenas 1 indicador considerado, representando 3\% do total de indicadores), principalmente em função da variável ambiental que agrupa 17 dos 32 indicadores existentes ( $53 \%$ do total), seguido pelo pilar das demandas sociais (com $25 \%$ do total de indicadores) e em terceiro o pilar Decisões Políticas (19\%).

Para buscar diminuir esta diferença entre o peso das dimensões, é recomendado que seja ampliada a avaliação da dimensão econômica, observando a capacidade de gerar recursos provenientes de setores da nova economia de baixo carbono que está se desenvolvendo, o peso do setor de serviços na geração total de receitas, o nível de concentração de renda da região, a renda média da região, se existem instrumentos de estímulo a comportamentos mais zelosos com os recursos naturais - desestimulando o desperdício de recursos, estimulando o reuso e a reciclagem, desestimulando a especulação imobiliária e de terras, são alguns exemplos.

Podemos observar pelos gráficos apresentados que apesar da filosofia focada no ser humano e na relação harmoniosa com a natureza, a estância Demétria não apresenta uma pontuação muito superior ao município de Botucatu. Podemos atribuir à estância, baseados na pontuação bastante semelhante à de Botucatu, o mesmo selo atribuído ao município: Eficiência.

As dimensões onde a Estância Demétria apresenta maior pontuação em relação ao município de Botucatu são a ambiental pela conservação das águas e requalificação ambiental e a social pelo maior envolvimento comunitário e política em função da possibilidade de melhores locações preferenciais, já Botucatu se sobressai na dimensão econômica em função da maior diversidade de atividades econômicas.

Importante ressaltar que um aumento na representatividade nas entrevistas da pesquisa poderia alterar os resultados obtidos, uma vez que a amostra utilizada para a pesquisa foi de representantes de três estruturas existentes na Estância. 


\section{ANEXO A: QUESTÕES ESCOLA AITIARA - CRITÉRIOS SELO LABVERDE}

\section{Eficiência Energética}

1.1 A escola possui sistema próprio de geração de energia elétrica? Quais são?

1.2 Apresenta medidas para redução de uso de energia, tais como iluminação natural, ventilação cruzada, isolamento térmico?

1.3 Utiliza lâmpadas de baixo consumo (LEDs, fluorescentes)?

1.4 Utiliza sistema de captação de energia solar para aquecimento de água?

\section{Abastecimento e uso de água}

2.1 As instalações da escola utilizam sistema de captação de águas pluviais?

2.2 Utiliza sistemas de reciclagem de águas servidas (cinza/negras)? Quais? É feito reúso dessa água?

2.3 Existem mecanismos de redução de consumo (banheiros secos, bacias sanitárias com caixa acoplada, torneiras com vazão controlada)?

\section{Reuso do Edifício}

3.1 O edifício foi reformado para instalação da escola, ou foi construído para abrigála?

3.2 As instalações da escola tem outros usos fora dos horários e dias de aula?

\section{Minimização de distúrbios durante a construção}

4.1 Durante as obras (construção/reforma) foram utilizadas medidas para redução de distúrbios (ruídos, gestão de resíduos, tráfego de veículos e pedestres)? Se sim, quais medidas?

\section{5. Área Verde}

5.1 Como foi planejada a integração com a vegetação do entorno em relação à: Redução de ilha de calor Ruídos externos Área permeável

\section{Gestão de resíduos}

6.1 As instalações da escola prevêem local adequado para:

Coleta do lixo reciclável?

Compostagem de orgânicos?

Armazenagem de resíduos até a retirada? 
6.2 Existe coleta seletiva de resíduos?

6.3 Qual é o destino final dos tipos de resíduos coletados?

\section{Escolha de materiais e técnicas construtivas}

7.1 Que materiais foram utilizados na construção/reforma da escola?

7.2 Quais foram os critérios para a escolha? (custos/disponibilidade de material e mão de obra na região/estética/ciclo de vida e impacto ambiental/outros)

\section{Envolvimento Comunitário}

8.1 Houve envolvimento da comunidade durante:

Definição da localização do edifício/escolha do terreno?

Definição do programa de necessidades (espaços que escola abrigaria)?

Escolha de técnicas construtivas/materiais?

Projeto?

Construção/reforma?

8.2 Quais comunidades foram envolvidas (gestores da escola/moradores Demétria/ alunos/pais de alunos/moradores bairros vizinhos/outros)

8.3 De que forma se deu o envolvimento (reuniões para apresentação/colsulta, reuniões deliberativas /oficinas/grupos de trabalho/outros)

\section{ANEXO B: QUESTÕES DE ESCALA REGIONAL, URBANA E SETORIAL - CRITÉRIOS SELO LABVERDE}

1. Há representante do Bairro Demétria nas atividades de algum Comitê de Bacias?

2. Há gestão das águas superficiais e subterrâneas no bairro? Há cuidados para que não sejam poluídas?

3. Há preservação e/ou conservação das florestas e matas nativas no bairro?

4. Qual o destino do lixo? Há coleta e reciclagem?

5. Há alguma geração de energia elétrica por água, vento, placa solar ou biodigestão?

6. Há controle do número de habitantes e quantidades de casas no bairro? 
7. Como é o envolvimento comunitário?

8. Há áreas com erosão ou contaminação de produtos químicos ou esgoto? Essas áreas receberam novos usos?

9. Para as construções das casas são considerados os cursos de água, topos de morro, áreas de várzea e de mata?

10. Há parques e áreas verdes comuns?

11. Há ciclovias instaladas ou em planejamento?

12. Há encostas ou áreas com risco de desabamento? Qual o cuidado com essas áreas?

13. Ocorrem enchentes nas casas ou estradas do bairro? Quais atitudes são tomadas?

14. As habitações são construídas verticalmente e aglomeradas ou espaçadas e térreas?

15. Como é o uso do solo e do espaço? Há diversidade de usos?

16. Há acesso a diversos tipos de moradias?

17. Há ruas de pedestres ou trilhas?

18. A rede viária é eficiente? Possui ciclovia?

19. A acessibilidade á Estância pode ser feita com facilidade a pé, com bicicleta, transporte público e carro?

20. Há envolvimento da comunidade com as ações da Estância? 


\section{REFERÊNCIAS}

BERTALOT-BAY, Marco Michele (2008). Conseqüências ambientais e sociais da atividade agrícola: reflexões epistemológicas sobre a regenerabilidade. Dissertação de mestrado. Universidade Estadual De Campinas Instituto De Geociências PósGraduação Em Geografia Área Análise Ambiental E Dinâmica Territorial.

Escola Aitiara. <www.aitiara.org.br>. Acessado em 08 de novembro de 2011.

Estância Demétria. <http://www.demetria.com.br/portal/>. Acessado em 10 de novembro de 2011.

ELKINGTON, J. (1999). Triple bottom line revolution: reporting for the third milIennium. Australian CPA, v. 69.

FRY, T. (2005). Contra uma Teoria Essencialista de Necessidade: Algumas Considerações para a Teoria do Design. Revista Design em Foco, janeiro-junho, ano/vol. II, número 001, pp 63-77. Bahia: Universidade do Estado da Bahia.

MANZINI, E., VEZZOLI, C. (2002). O Desenvolvimento de Produtos Sustentáveis: os requisitos ambientais dos produtos industriais. São Paulo: Edusp (Trad. Astrid de Carvalho).

PENTEADO, H. (2003). Ecoeconomia: uma nova abordagem. São Paulo: Lazuli.

REIGOTA, M. A. S. (coord.); CATUNDA, M. B.; PETRAGLIA, M.S.; SINTO, C.M. (2011). Ecoando Ressonâncias Da Educação Ambiental: Descobertas, Conflitos, Diálogos; Por Uma Ecologia Sonora Sensível. In European Review Of Artistic Studies.

SACHS, I. (2002). Caminhos para o desenvolvimento sustentável. Rio de Janeiro: Garamond.

Sociedade Antroposófica do Brasil. <http://www.sab.org.br/antrop/>. Acessado em 08 de novembro de 2011. 
UNEP - United Nations Environment Programme (2004). Agenda of the Twentythird session of the governing council. Nairobi: UNEP.

VEIGA, J. E. (2005). Do global ao local (2005b). Campinas: Armazém do Ipê. 